\section{In honour of Lanczos}

Studies in Numerical Analysis. (Papers in Honour of Cornelius Lanczos.) Edited by B. K. P. Scaife. Pp. xxii +333 . (Academic: London and New York, September 1974. Published for Royal Irish Academy.) £5.00; $\$ 13.00$.

ThIS Festschrift volume is published under the auspices of the Royal Irish Academy as a tribute to Cornelius Lanczos on the occasion of his 80th birthday (February 2, 1974). It is devoted almost exclusively to numerical analysis, since, although Lanczos made significant contributions to areas of theoretical physics, he is most widely known for his work in this particular field. Professor Lanczos died in Budapest on June 24, 1974 but, happily, he had lived to see this personal and affectionate tribute to him from many distinguished scholars.

Lanczos was educated in Hungary and worked first in Germany (192231 ), then in the United States (193154), and lastly in Eire (1954-74), and he was completely imbued and enthused with the traditional viewpoint of the complementary interaction between mathematics and physics, as exemplified by the Göttingen school of mathematics founded by David Hilbert. His work may be divided into two main areas: relativity theory and quantum theory (1922-38) and numerical analysis (1938-74), and in both of these he made important and lasting contributions to knowledge; his abiding interest lay with geometry and the nature of space and time. Lanczos was a prolific author of papers and books, which show clearly his viewpoint of the essential unity of mathematics and physics (the viewpoint, for example, of John von Neumann) and their cultural appeal and importance (as, for example, discussed by Morris Kline).

The Festschrift opens with a biographical note on Lanczos, supplemented by a list of publications by him (94 articles and eight books), and it continues with 19 contributed articles. Professor B. K. P. Scaife, who has charmingly dated his editor's foreword for Lanczos' birthday, has obviously sought, by the particular choice of contributers, to associate as far as possible current developments in numerical analysis with Lanczos's original ideas in that field. These include the application of Chebyshev polynomials in approximation theory and the development of the economisation (or telescoping) method and the tau method (1938); the fast-Fourier transform (1942); the first exact method for obtaining all the eigenvectors and eigenvalues of an arbitrary matrix (1951); a fundamental theorem on the decomposition of an arbitrary matrix (1958); a precision approximation to the Gamma function (1964); and Sigma factors for smoothing Gibbs's oscillations in Fourier series (1966).

In summary, in addition to articles of a specialist nature on topics in numerical analysis, there are three articles of a biographical nature and also a review article on conservation laws in Einstein's general theory of relativity. The book will appeal especially to those with interests in numerical analysis and also to those interested in the life and achievements of Cornelius Lanczos.

H. G. Hopkins

\section{Red tide}

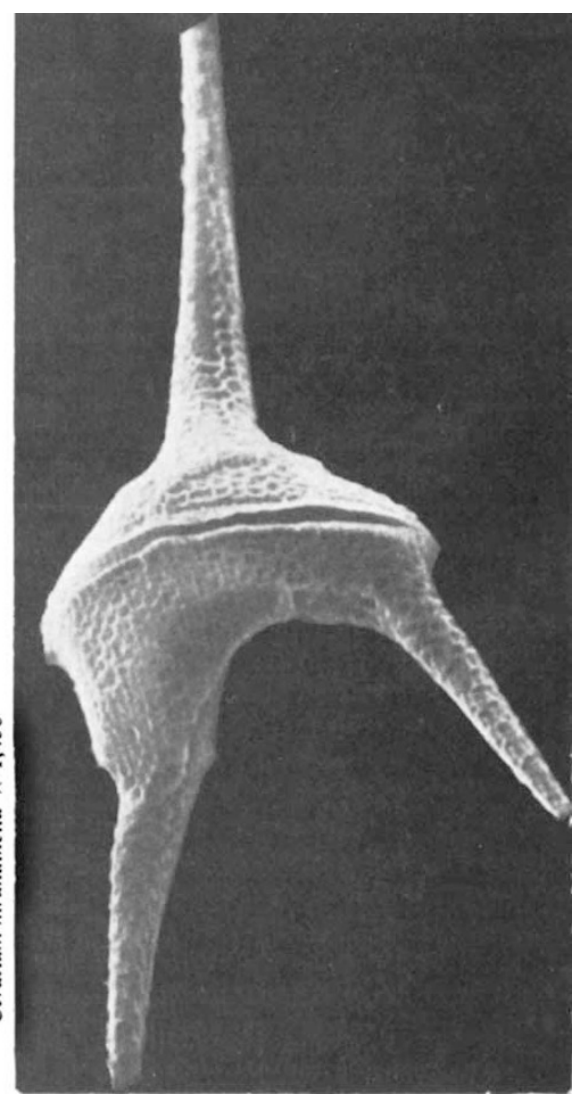

Fossil and Living Dinoflagellates. By W. A. S. Sarjeant. Pp. vii +182 . (Academic: London and New York, December 1974.) $£ 5.00 ; \$ 13.00$.

The gulf called Sinus arabicus by the Romans was known to the Arabs themselves as the Red Sea, and it was under that name that it became known to the rest of the civilised world at least as long ago as the ninth century. The visually spectacular effects of the 'red tide' blooms of dinoflagellates have been recognised, therefore, for over 1,000 years, but not until the publication of this work has a book been devoted solely to these extraordinary organisms. Even if there were no other reason, that aspect alone must recom- mend Dr Sarjeant's volume, but the whole has the additional merits of clarity, readability and profuse, well chosen illustrations. The publishers maintain their high standards with good quality paper, clear printing and format, and strong and attractive binding.

Dr Sarjeant is a palynologist and micropalaeontologist; originally, he intended to deal only with the fossil dinoflagellates and their resting cysts ('hystrichospheres'), and it is with these that his strength lies. Appropriate techniques of sample preparation are outlined clearly and fully, thecate dinoflagellates and cysts are described morphologically, and a separate short chapter is devoted to the taxonomic problems which have resulted from nomenclature based separately upon thecae and cysts. A concise but thorough suprageneric classification of fossil dinoflagellates is appended, and the stratigraphic history of the group is summarised. The acritarchs are mentioned but not described in detail, and there are no illustrations or descriptions of the great majority of the genera and species listed in the stratigraphic section; the reader must turn to the references given by the author for that information. Recent attempts to achieve an objective terminology for the description of cyst walls are not discussed at all. Otherwise, the account is very comprehensive, and it is invaluable to have it (ard such a valuable collection of reference lists) now so conveniently to hand.

The chapters dealing with biology, ecology (12 pp.) and palaeoecology (6 pp.) are much less thorough. The faculty possessed by some species to generate extraordinary levels of bioluminescence, with marked periodicity, still deserves further treatment-not only for its own sake, but also for the field work it has stimulated which is contributing greatly to our knowledge of the ecology of these organisms. Much detailed ecological work has been done in recent years, not least in the Red Sea itself, where dinoflagellates dominate primary production for most of the year. The important role played by dinoflagellates in food webs deserves more attention: symbiotic dinoflagellates (zooxanthellae) form a significant primary role in the productivity of coral reefs, and the motile swarms of the 'red tide' itself make their contribution to nutrition as well as to spectacular mass mortalities.

Dr Sarjeant's book will surely deserve a second edition on the merit of its micropalaeontology alone; if neontology and ecology could then be equally well covered, it would undoubtedly be a major contribution to synoptic studies in the natural sciences.

F. T. Banner 